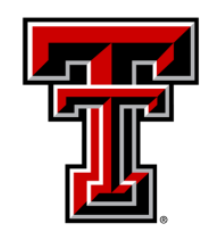

TEXAS TECH UNIVERSITY

Libraries"

\title{
UnderuSEd Methods in DeVELOPMENTAL SCIENCE to INFORM Policy AND PRACTICE
}

\section{The Texas Tech community has made this publication openly available. Please share how this access benefits you. Your story matters to us.}

\begin{tabular}{|l|l|}
\hline Citation & $\begin{array}{l}\text { Rioux, C. \& Little, T. D. (2020). Underused methods in } \\
\text { developmental science to inform policy and practice. Child } \\
\text { Development Perspectives. 14(2), 97-103. } \\
\text { https://doi.org/10.1111/cdep.12364 }\end{array}$ \\
\hline Citable Link & $\underline{\text { https://hdl.handle.net/2346/86922 }}$ \\
\hline Terms of Use & $\begin{array}{l}\text { This is the peer reviewed version of the article, which has been } \\
\text { published in final form at the above citation. This article may be } \\
\text { used for non-commercial purposes in accordance with Wiley Terms } \\
\text { and Conditions for Use of Self-Archived Versions. }\end{array}$ \\
\hline
\end{tabular}


Accepted manuscript published in Child Development Perspectives - full reference:

Rioux, C. \& Little, T. D. (2020). Underused methods in developmental science to inform policy and practice. Child Development Perspectives. 14(2), 97-103. doi: 10.1111/cdep.12364.

Underutilized Methods in Developmental Science to Inform Policy and Practice

Charlie Rioux and Todd D. Little

Texas Tech University

Author note:

Authorial contribution is equivalent with order determined by mentee/mentor relationship.

Charlie Rioux, Department of Educational Psychology and Leadership, Texas Tech University.

Todd D. Little, Department of Educational Psychology and Leadership, Texas Tech University. Also affiliated with Optentia Research Focus Area, North-West University, Vanderbijlpark, South Africa.

Acknowledgements: This article was supported, in part, by the Canadian Institute of Health Research through a fellowship to CR and the Fonds de Recherche du Québec - Santé through a fellowship to CR.

Correspondence concerning this article should be addressed to Charlie Rioux, charlie.rioux@ @ttu.edu, or Todd D. Little, todd.d.little@ttu.edu 


\begin{abstract}
In this commentary, we selectively offer some recommendations for underutilized innovations and advances in methodology that would enhance the quality of developmental science research. We couch our recommendations in terms of measurement innovations, design innovations, and analytic advances. We conclude with an exhortation to developmental scientists to continue to incorporate advances and innovations in methodology as they address the essential questions surrounding our goal to understand and improve the human condition across the life span.
\end{abstract} Keywords: Methodology, Best-practices, Methods innovations 
Underutilized Methods in Developmental Science to Inform Policy and Practice Advancing developmental science to inform policy and practice necessitates rigorous research methods. Indeed, using sophisticated methods adapted to the research questions being examined, and that have been shown to be associated with the most accurate results, is primordial to provide the best foundation for effective policy and practice. Developmental methods are constantly evolving, but some rigorous research methods, even when they have been proposed for decades, remain underutilized. This lack of adoption is due to many factors, including that the lack of utilization can make some slip through the cracks, with few researchers knowing about them, and also a lack of advanced technology when some methods were proposed. Developmental scientists have a wealth of advances and innovations to incorporate into their research toolbox. In this invited commentary, we selectively highlight six of these methods that are underutilized in the areas of measurement, design, and analysis.

\section{Measurement}

\section{The visual analog scale}

An important issue for developmental research using self-reports is obtaining the most accurate answer possible. Many constructs of developmental research are continuous in nature and would thus best be measured by an interval scale, but the most common scale is the Likert scale, which is an antiquated ordinal scale. Likert introduce the convenient method in 1932 as a means of reducing error and simplifying data collection (Likert, 1932); but this convenience came at an expense even in 1932. Today with automated and accurate electronic collection methods readily available, we can and must move away from Likert-like scaling to incorporate and easily implement better collection methods. 
An alternative to the Likert scale is the visual analog scale, which consists of a continuous number line with endpoint verbal anchors (and perhaps a midpoint anchor). Historically, this interval scale was difficult to implement as it required researchers to manually measure the participants' responses using rulers, which made the Likert scale a more efficient option. With technological advancements however, the visual analog scale is now an efficient and often more valid option. Papers published in $2019(n=634)$ in four developmental journals (Child Development, Development and Psychopathology, Developmental Psychology, Developmental Science) were reviewed for mentions of the methods highlighted in this commentary, and the visual analog scale was mentioned in only two articles, confirming that it is still rarely used in developmental research.

The visual analog scale allows researchers to appropriately capture continuous constructs and respondents to freely specify their level of agreement with an item, instead of being constrained to predetermined categories. This advantage is an important one because measuring a continuous construct with a Likert scale can collapse different true scores into the same category, an issue referred to as scale coarseness that can introduce systematic measurement bias (Aguinis, Pierce, \& Culpepper, 2009). This measurement bias is reduced as the number of answer categories increase and is completely avoided by using a truly continuous scale such as the visual analog scale. Furthermore, data collected with the visual analog scale was shown to be more precise and provides more information than the Likert scale (Funke \& Reips, 2012; Rausch \& Zehetleitner, 2014). Moreover, the visual analog scale was found to be valid, reliable, efficient to administer, and easy to use (and intuitive) for participants (e.g., Abend, Dan, Maoz, Raz, \& Bar-Haim, 2014; Delgado et al., 2018; Jollant et al., 2019; Steiner \& Streiner, 2005). To ensure participants can familiarize themselves with the procedure, it is easy (and recommended) to 
accompany the visual analog scale with a brief introduction with instructions and a couple examples or practice questions. Although there are many advantages to the visual analog scale, as mentioned above its easy implementation requires a computerized questionnaire. Accordingly, for studies with populations or designs that require the use of paper questionnaires, the Likert scale is more convenient and may have more advantages than disadvantages.

The visual analog scale can also be adapted to better measure change by labeling the midpoint of the scale with an anchor such as "no change" and then labelling the endpoints with an appropriate direction of change such as "Less Interest" and "More Interest," respectively (see e.g., Allen et al., in press). This direct assessment of change would open up a wealth of opportunity to capture continuous growth or change across the span of a given study while avoiding some ceiling effects. When developmentalists use tradition repeated assessments that are not directly adapted to capture change, we find many measurement artifacts that emerge such as an artificial negative correlation between intercept and slope in growth models (Little, 2013).

\section{The retrospective pretest-posttest}

Program evaluations are an important aspect of developmental research. Most of this research uses a pretest-posttest design, in which the baseline of the outcome of interest is measured before the intervention is administered, and then measured again after the intervention. An alternative to the traditional pretest-posttest design is the retrospective pretest-posttest design, in which both the baseline and post-intervention levels of the outcome are measured after the intervention. Accordingly, when data is collected after the intervention, participants are administered questions that ask about their current status on the outcome (i.e., posttest), and that ask to retrospectively recall their perceived status prior to the intervention (i.e., pretest). None of the 634 papers reviewed mentioned the retrospective pretest-posttest. 
Traditional pretests can fail to identify intervention effects because they are susceptible to response shift bias. This bias occurs when participants' frame of reference regarding the question changes between the pretest and posttest, making it difficult to compare their answers and make accurate conclusions regarding the effectiveness of the intervention (G. S. Howard, 1980). This shift is an especially important concern when the intervention has the potential to change participants' understanding and awareness of the study's outcome variable. Indeed, participants tend to overestimate their initial levels in traditional pretests because they do not have sufficient knowledge about their attitudes, behaviors or skills before the intervention (Nimon \& Allen, 2007). If the intervention increases their knowledge or makes them more aware of their actual levels, their frame of reference about the construct changes and participants no longer have the same tendency to overestimate at the posttest, making the two assessments incomparable. By administering the pretest and posttest at the same time, the retrospective pretest-posttest design is not susceptible to response shift bias. Research supports the validity of the retrospective pretestposttest design, showing that it is more sensitive to expected intervention effects compared to the traditional pretest-posttest when response shift bias is present (e.g., Nakonezny \& Rodgers, 2005; Pratt, McGuigan, \& Katzev, 2000; Sprangers et al., 1999) and that they are sensitive to the effects of interventions even when no pretest data is collected (Little et al., 2019). While the possibility of children's and adolescents' cognitive development could limit their ability to answer retrospective questions, a study showed that 9-year-old participants were able to retrospect on their initial status, and thus appropriately answer a retrospective pretest (Little et al., 2019). A thorough review of the pros and cons of this measurement approach is beyond the scope of this commentary, but Little et al. (2019) provide an extensive re-introduction of it. 


\section{Design}

\section{Appropriate timing and units of change}

Developmental research relies heavily on longitudinal panel studies to examine change. Valid results in these studies are dependent on the timing of measurement and the pace of change being in sync. This synchrony is important since when the time lag between measurement occasions is not optimal, relations between variables are often underestimated (Cole \& Maxwell, 2009). This synchrony between the timing of measurement and the pace of change is rarely found in current research however, and as Cole and Maxwell (2003) noted, the timing of measurement in social sciences is often determined by convenience and tradition instead of by theory and research. Still, designing a study with proper timing of measurement can be difficult, as some theories do not elaborate on when and how quickly change is expected to occur (Mitchell \& James, 2001). Nevertheless, researchers should carefully consider previous theory and longitudinal research in establishing the ideal timing of measurement. When theory and previous evidence cannot fully inform the optimal lag, it can be calculated using data from previous studies or a pilot study with short time lags (see Dormann \& Griffin, 2015). Although theory sometimes details specific time lags for developmental processes to occur, in many cases the underlying theory may also be that the interinfluence between two variables occurs continually over time, and thus discrete time measurements can only capture snapshots of this process. In these cases, ideal timing of measurement would often be considered as the lag that would yield the largest effect size of the association between the variables of interest (Dormann \& Griffin, 2015).

In a related vein, discrete measurement occasions often are separated by variable intervals due to the logistics of data collection. The time between measurements for each person 
varies as a function of when in the window period of a measurement the person was assessed. This lag in measurement at the person level can be measured and used as an important variable in subsequent analyses. Selig, Preacher, \& Little (2012) describe how to calculate this lag variable and then utilize it in the analysis model as a moderator of any cross-time predictive relationships. When this moderator variable is significant, it indicates that the strength of the regression coefficient in question varies depending on the actual interval that each person had. Such models are different than analytical strategies that aim to capture continuous change with discrete measurement occasions (i.e., continuous time models (Voelkle, Oud, Davidov, \& Schmidt, 2012). The lag as moderator analysis model can be used to identify peak associations as a function of the time interval to inform the optimal discrete time interval (Selig, Hoy, \& Little, 2014; Selig et al., 2012).

In addition to proper timing of measurement, more attention needs to be given to the units used to index change. Indeed, in developmental science, most longitudinal studies index time using the measurement occasion or participants' age, notably because traditionally, developmentalists think of behavior as a function of age. This approach can be limiting, and it would be more accurate to think of change as a function of time, which would inform the right index of time to capture change in the construct of interest (Little, 2013). For example, grade in school is an index of episodic time and is a useful designation for modeling change in schoolrelated constructs. A child's relative age within his or her grade in school should also be calculated and included in subsequent analysis models. Relative age effects are under examined in most developmental contexts outside youth sport participation, but these effects are frequently found when this information is measured and included analytically. Many other units of time 
could be considered depending on the research questions, such as time before and/or after a specific developmental event (e.g., school entry, puberty, parental separation).

\section{The accelerated longitudinal design}

In a traditional longitudinal design, time of measurement, participant age, and cohort are confounded. An alternative design, the accelerated longitudinal design, allows to control for cohort and time of measurement effects, with the additional advantage of collecting data on a wider age range in less time. This design was used in five of the 634 reviewed studies.

The accelerated longitudinal design is a type of planned missing data design, which is defined as missing data that is controlled by the researcher. Because the missing data introduced by the researcher are missing completely at random (MCAR), it is recoverable using modern missing data treatments (see next section) without introducing any bias. Planned missing data designs can notably involve randomly assigning participants to assessments that include missing items (i.e., multiform design), missing measurement occasions (i.e., waver-missing design), or missing measures (i.e., three-form design; see Little and Rhemtulla (2013) for a review). In these three instances, the assessments themselves are incomplete by randomly assigning missing values before data collection. For the accelerated longitudinal design however, the data collection may be considered complete, but the dataset is formatted in such a way that missing data cells are introduced. Indeed, the accelerated longitudinal design is a transformation of the cross-sequential design, which starts with a cross-sectional design (with participants of different ages) and then follows all participants longitudinally (see Table 1). For the accelerated longitudinal design, this cross-sequential design is transformed into a dataset with the full span of ages represented by the sample and missing data cells when cohorts are not assessed for a specific age (see Table 1). This transformation allows the creation of variables representing 
cohort and time of measurement effects, which are then controlled for in the analysis model. Granted, such a transformation introduces complexity to the model with parameters that need careful interpretation; however, when properly specified and assumptions are met, this design provides unbiased estimates of age-related changes and differences across the agespan represented by the total sample. Note that although this example was based on age, an accelerated longitudinal design could also be used with other indexes of time (e.g., school grade, with the design starting with cohorts in different grades) when more suitable for the research questions (see previous section).

\section{Data analysis}

\section{Missing data treatments}

Missing data are ubiquitous in developmental research, especially longitudinal studies. Despite the increasing literature on appropriate missing data treatments, reviews of recent developmental research show that deletion techniques are still the most frequent missing data treatment (Lang \& Little, 2018; Rioux \& Little, 2019), and evidence shows that deletion methods are associated with lower power and biased parameter estimates. If there are missing data, appropriate missing data treatments should be used regardless of the study design or amount and type of missing data. These missing data treatments include multiple imputation and full information maximum likelihood (FIML), which are the recommended approaches in the vast majority of instances (there are some exceptions, e.g., time-to-event analyses may use imputation or censoring (Rioux \& Little, 2019)). FIML is a model-based approached that deals with the missing data by estimating parameters and standard errors in a single step but can only be used for data analyses for which maximum likelihood estimation is applicable. Multiple imputation is a two-step approach in which missing values are first estimated to create imputed data sets, and 
analyses are then run on the imputed data sets. Multiple imputation and FIML were mentioned in 136 of the 634 reviewed articles but should be used in almost all instances where there are missing data.

These missing data treatments should be properly implemented (see, e.g., Enders, 2010; Lang \& Little, 2018), notably by including auxiliary variables; that is, variables that are not examined for the objectives of the study, but that are included as predictors of missingness. Unfortunately, many studies using appropriate missing data treatments, especially when using FIML, do not mention the inclusion of auxiliary variables (Lang \& Little, 2018; Rioux \& Little, 2019). This omission is particularly problematic since auxiliary variables are necessary to meet the assumptions of missing at random (MAR) for accurate estimation with multiple imputation or FIML and failing to include them has been shown to bias results (W. J. Howard, Rhemtulla, \& Little, 2015). Proper reporting of missing data rates and treatments should be the norm, and should be required by developmental journals; Articles (in the main manuscript, or in supplementary materials) should report the rates, reasons, and mechanisms for missing data, state the missing data handling procedure, and describe all decisions made when handling the missing data.

\section{Integrative data analysis}

Data sharing and secondary data analyses are becoming increasingly common in developmental research (Friedman, 2007; Greenhoot \& Dowsett, 2012), especially since many developmental questions require extensive longitudinal data. An analytical framework that can enhance secondary data analyses is integrative data analysis (Bainter \& Curran, 2015; Curran \& Hussong, 2009; Hussong, Curran, \& Bauer, 2013). Integrative data analysis aims to pool raw data from two or more studies before conducting data analyses on the combined data and making 
inferences both between and within studies. To do so, psychometric modeling techniques are used to create measures with the same meaning and scale across studies despite initial differences in the assessments. Items unique to one study may be included, but some common items are needed to link the measurement across studies. Such common items need to have the same prompt and response scale, but if the original items were not identical, they can often be harmonized by combining categories, items, or responses. Furthermore, techniques can be used to control sources of between-study heterogeneity for study integration, and study differences can also be examined as potential moderators of the results, providing information about the generalizability of findings. Any source of between-study heterogeneity may be considered, notably sampling, geographical region, historical time, and other design characteristics. Depending on the studies examined, however, different sources of heterogeneity may be confounded, limiting the ability to distinguish them in the integrative analyses (Curran \& Hussong, 2009). Integrative data analysis was not used in any of the 634 articles reviewed. Integrative data analysis can have many advantages (Bainter \& Curran, 2015; Curran \& Hussong, 2009; Hussong, Curran, \& Bauer, 2013), which depend on the contributing data sets and research questions examined. A main advantage is increased sample size. A larger sample size increases power and can provide enough participants to study rare behaviors or disorders. Furthermore, this larger pooled sample may also be more diverse when the individual samples underrepresent some racial, ethnic, and socioeconomic groups, which increases external validity and allows direct comparisons across subgroups. Integrative data analysis also contributes to both replication and integration of findings by examining results between and within studies. Because integrative data analysis incorporates the methods of assessment used in each study, the psychometric assessment of constructs is broadened and can result in stronger psychometric 
properties. In some cases, integrative data analysis can also allow examining a longer developmental period than the periods available in each individual study; as long as there is some overlap in timing of measurement (e.g., ages), the models can be estimated with proper missing data treatments. Studies are pooled based on cohort sequential methods (Hussong et al., 2013), which can yield a similar missing data pattern as presented above for the accelerated longitudinal designs, except that each "cohort" is from a different original study, and the assessments available for each cohort would depend on the design of each study. Finally, integrative data analysis can also be used to pool multiple reporter assessments (e.g., motherreport, father-report, teacher-report), even if each individual study did not have all reporters, as long as there is enough overlap for missing data estimation (Curran et al., in press). Despite these advantages, integrative data analysis is not always feasible, such as when there are not enough common items, or when confounded between-study characteristics are central to the research question (Bainter \& Curran, 2015). In such cases, integrative data analysis either is not feasible or does not provide the information necessary for a specific research question. Future studies could be designed to facilitate integrative data analysis, such as by using the same measures or making sure to have enough common items between studies.

There is no standardized technique for integrative data analysis, but rather a set of principles that act as a guiding framework. Recommendations for conducting integrative data analysis can be found in Bainter \& Curran (2015), Curran \& Hussong (2009), and Hussong, Curran, \& Bauer (2013).

\section{Conclusion}

Developmental science, historically, has shown a willingness to adopt new developments and advances in methodology. Still, some rigorous research methods remain underutilized in the 
field. We have reviewed six of these methods, namely the visual analog scale, the retrospective pretest-posttest, the timing and units of change, the accelerated longitudinal design, appropriate missing data treatments, and integrative data analysis. Still, this list was selective, and many more methodologies could be taken into consideration more frequently for advancing developmental science (such as intensive longitudinal designs (Bolger \& Laurenceau, 2013), confirmatory factor analysis and invariance testing (Little, 2013), parceling (Little et al., 2013) etc.). We exhort developmental scientists to continue to incorporate advances and innovations in methodology as they address the essential questions surrounding our goal to understand and improve the human condition across the life span. To serve social justice by providing the most valid findings for policy and practice, our field needs to continue to stay at the cutting edge of methodological developments and incorporate them readily into research practice. 


\section{References}

Abend, R., Dan, O., Maoz, K., Raz, S., \& Bar-Haim, Y. (2014). Reliability, validity and sensitivity of a computerized visual analog scale measuring state anxiety. Journal of Behavior Therapy and Experimental Psychiatry, 45(4), 447-453.

doi:10.1016/j.jbtep.2014.06.004

Aguinis, H., Pierce, C. A., \& Culpepper, S. A. (2009). Scale Coarseness as a Methodological Artifact Correcting Correlation Coefficients Attenuated From Using Coarse Scales. Organizational Research Methods, 12(4), 623-652. doi:10.1177/1094428108318065

Allen, P. J., Chang, R., Gorrall, B. K., Waggenspack, L., Fukuda, E., Little, T. D., \& Noam, G. G. (in press). From quality to outcomes: A national study of afterschool STEM programming. International Journal of STEM Education.

Bainter, S. A., \& Curran, P. J. (2015). Advantages of Integrative Data Analysis for Developmental Research. Journal of Cognition and Development, 16(1), 1-10. doi:10.1080/15248372.2013.871721

Bolger, N., \& Laurenceau, J.-P. (2013). Intensive Longitudinal Methods: An Introduction to Diary and Experience Sampling Research. New York, NY: The Guildford Press.

Cole, D. A., \& Maxwell, S. E. (2003). Testing mediational models with longitudinal data: Questions and tips in the use of structural equation modeling. Journal of Abnormal Psychology, 112(4), 558-577. doi:10.1037/0021-843x.112.4.558

Cole, D. A., \& Maxwell, S. E. (2009). Statistical Methods for Risk-Outcome Research: Being Sensitive to Longitudinal Structure. Annual review of clinical psychology, 5, 71-96. doi:10.1146/annurev-clinpsy-060508-130357 
Curran, P. J., Georgeson, A. R., Bauer, D. J., \& Hussong, A. M. (in press). Psychometric Models for Scoring Multiple Reporter Assessments: Applications to Integrative Data Analysis in Prevention Science and Beyond. International Journal of Behavioral Development.

Curran, P. J., \& Hussong, A. M. (2009). Integrative Data Analysis: The Simultaneous Analysis of Multiple Data Sets. Psychological Methods, 14(2), 81-100. doi:10.1037/a0015914

Delgado, D. A., Lambert, B. S., Boutris, N., McCulloch, P. C., Robbins, A. B., Moreno, M. R., \& Harris, J. D. (2018). Validation of Digital Visual Analog Scale Pain Scoring With a Traditional Paper-based Visual Analog Scale in Adults. Journal of the American Academy of Orthopaedic Surgeons Global Research and Reviews, 2(3), 6. doi:10.5435/JAAOSGlobal-D-17-00088

Dormann, C., \& Griffin, M. A. (2015). Optimal Time Lags in Panel Studies. Psychological Methods, 20(4), 489-505. doi:10.1037/met0000041

Enders, C. K. (2010). Applied Missing Data Analysis. New York, NY: The Guildford Press.

Friedman, S. L. (2007). Finding treasure: Data sharing and secondary analysis in developmental science. Journal of Applied Developmental Psychology, 28(5-6), 384-389. doi:10.1016/j.appdev.2007.07.001

Funke, F., \& Reips, U. D. (2012). Why Semantic Differentials in Web-Based Research Should Be Made from Visual Analogue Scales and Not from 5-Point Scales. Field Methods, 24(3), 310-327. doi:10.1177/1525822x12444061

Greenhoot, A. F., \& Dowsett, C. J. (2012). Secondary Data Analysis: An Important Tool for Addressing Developmental Questions. Journal of Cognition and Development, 13(1), 218. doi:10.1080/15248372.2012.646613 
Howard, G. S. (1980). Response-Shift Bias: A Problem in Evaluating Interventions with Pre/Post Self-Reports. Evaluation Review, 4(1), 93-106. doi:10.1177/0193841x8000400105

Howard, W. J., Rhemtulla, M., \& Little, T. D. (2015). Using Principal Components as Auxiliary Variables in Missing Data Estimation. Multivariate Behavioral Research, 50(3), 285-299. doi:10.1080/00273171.2014.999267

Hussong, A. M., Curran, P. J., \& Bauer, D. J. (2013). Integrative Data Analysis in Clinical Psychology Research. Annual review of clinical psychology, 9, 61-89. doi:10.1146/annurev-clinpsy-050212-185522

Jollant, F., Voegeli, G., Kordsmeier, N. C., Carbajal, J. M., Richard-Devantoy, S., Turecki, G., \& Caceda, R. (2019). A visual analog scale to measure psychological and physical pain: A preliminary validation of the PPP-VAS in two independent samples of depressed patients. Progress in Neuro-Psychopharmacology \& Biological Psychiatry, 90, 55-61. doi:10.1016/j.pnpbp.2018.10.018

Lang, K. M., \& Little, T. D. (2018). Principled Missing Data Treatments. Prevention Science, 19(3), 284-294. doi:10.1007/s11121-016-0644-5

Likert, R. (1932). A technique for the measurement of attitudes. Archives of Psychology, 22(140), 1-55.

Little, T. D. (2013). Longitudinal Structural Equation Modeling. New York, NY: The Guildford Press.

Little, T. D., Chang, R., Gorrall, B. K., Waggenspack, L., Fukuda, E., Noam, G. G., \& Allen, P. J. (2019). The retrospective pretest-posttest design redux: On its validity as an alternative to traditional pretest-posttest measurement. International Journal of Behavioral Development. 
Little, T. D., \& Rhemtulla, M. (2013). Planned Missing Data Designs for Developmental Researchers. Child Development Perspectives, 7(4), 199-204. doi:10.1111/cdep.12043

Little, T. D., Rhemtulla, M., Gibson, K., \& Schoemann, A. M. (2013). Why the Items Versus Parcels Controversy Needn't Be One. Psychological Methods, 18(3), 285-300. doi:10.1037/a0033266

Marsh, H. W., Morin, A. J. S., Parker, P. D., \& Kaur, G. (2014). Exploratory Structural Equation Modeling: An Integration of the Best Features of Exploratory and Confirmatory Factor Analysis. Annual review of clinical psychology, 10, 85-110. doi:10.1146/annurev-clinpsy032813-153700

Mitchell, T. R., \& James, L. R. (2001). Building better theory: Time and the specification of when things happen. Academy of Management Review, 26(4), 530-547. doi: $10.2307 / 3560240$

Nakonezny, P. T., \& Rodgers, J. L. (2005). An empirical evaluation or the retrospective pretest: Are there advantages to looking back? Journal of Modern Applied Statistical Methods, 4, 240-250.

Nimon, K., \& Allen, J. (2007). A review of the retrospective pretest: Implications for performance improvement evaluation and research. Workforce Education Forum, 44(1), $36-55$.

Pratt, C. C., McGuigan, W. M., \& Katzev, A. R. (2000). Measuring program outcomes: Using retrospective pretest methodology. American Journal of Evaluation, 21(3), 341-349. doi:10.1177/109821400002100305 
Rausch, M., \& Zehetleitner, M. (2014). A comparison between a visual analogue scale and a four point scale as measures of conscious experience of motion. Consciousness and Cognition, 28, 126-140. doi:10.1016/j.concog.2014.06.012

Rioux, C. \& Little, T. D. (2019). Missing data treatments in intervention studies: What was, what is, and what should be. International Journal of Behavioral Development. Advance online publication. doi: 10.1177/0165025419880609.

Selig, J. P., Hoy, R., \& Little, T. D. (2014). Temporal designs in organizational research. In M. Hassett \& E. Paavilainen-Mäntymäki (Eds.), Handbook of longitudinal research methods in studying organisations. (78-91). Cheltenham Glos, UK: Edward Elgar Publishing.

Selig, J. P., Preacher, K. J., \& Little, T. D. (2012). Modeling time-dependent association in longitudinal data: A lag as moderator approach. Multivariate Behavioral Research, 47, 697-716. doi:10.1080/00273171.2012.715557

Sprangers, M. A. G., Van Dam, F., Broersen, J., Lodder, L., Wever, L., Visser, M. R. M., .. . Smets, E. M. A. (1999). Revealing response shift in longitudinal research on fatigue The use of the thentest approach. Acta Oncologica, 38(6), 709-718.

Steiner, M., \& Streiner, D. L. (2005). Validation of a revised visual analog scale for premenstrual mood symptoms: Results from prospective and retrospective trials. Canadian Journal of Psychiatry-Revue Canadienne De Psychiatrie, 50(6), 327-332. doi:10.1177/070674370505000607

Voelkle, M. C., Oud, J. H. L., Davidov, E., \& Schmidt, P. (2012). An SEM Approach to Continuous Time Modeling of Panel Data: Relating Authoritarianism and Anomia. Psychological Methods, 17(2), 176-192. doi:10.1037/a0027543 


\section{I am curious about science.}

(a)

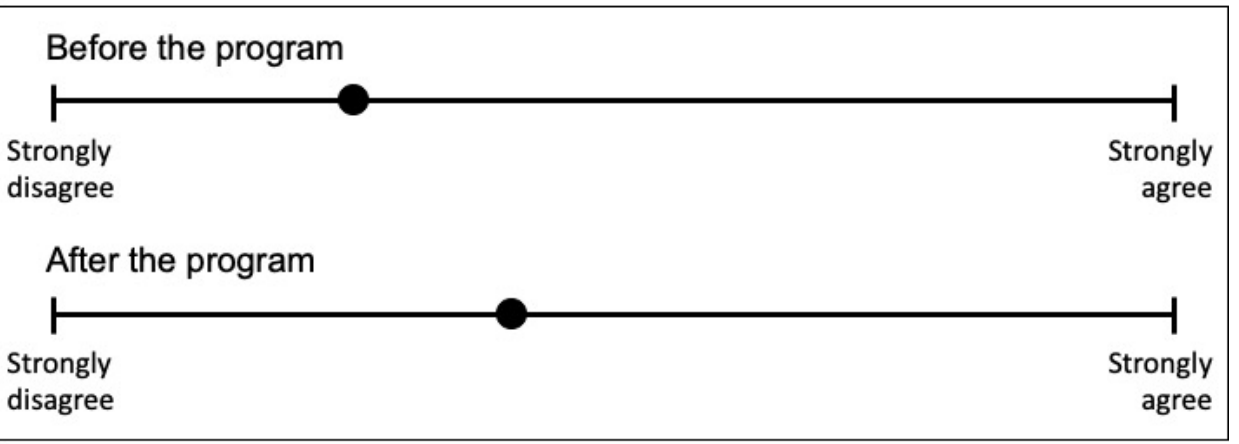

(b)

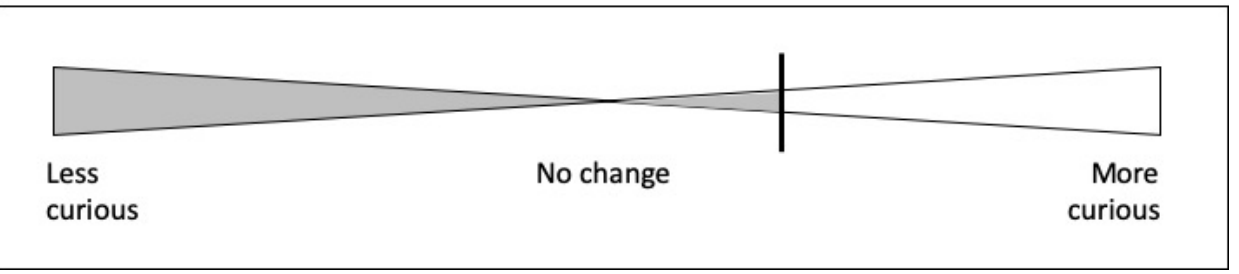

Figure 1. Example of a retrospective pretest-posttest item, with visual analog scales (a) measuring the variable of interest at pretest (retrospectively) and posttest, and (b) directly measuring change. 
Table 1

Example of an accelerated longitudinal design covering childhood and adolescent years with six yearly assessments

\begin{tabular}{|c|c|c|c|c|c|c|c|c|c|c|c|c|c|c|c|c|}
\hline \multirow[b]{2}{*}{ Cohort initial age } & \multicolumn{16}{|c|}{$\begin{array}{l}\text { Initial cohort-sequential design for data collection } \\
\text { Age in years for each cohort at each wave }\end{array}$} \\
\hline & \multicolumn{15}{|c|}{ 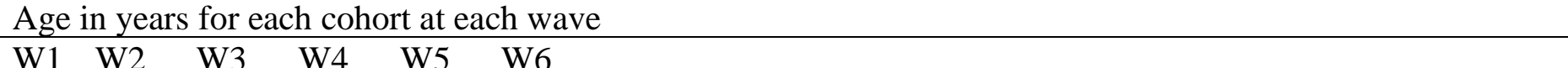 } & \\
\hline Age 1 years & 1 & 2 & 3 & 4 & 5 & 6 & & & & & & & & & & \\
\hline Age 3 years & 3 & 4 & 5 & 6 & 7 & 8 & & & & & & & & & & \\
\hline Age 5 years & 5 & 6 & 7 & 8 & 8 & 10 & & & & & & & & & & \\
\hline Age 7 years & 7 & 8 & 9 & 10 & 11 & 12 & & & & & & & & & & \\
\hline Age 9 years & 9 & 10 & 11 & 12 & 13 & 14 & & & & & & & & & & \\
\hline \multirow[t]{3}{*}{ Age 11 years } & 11 & 12 & 13 & 14 & 15 & 16 & & & & & & & & & & \\
\hline & \multicolumn{16}{|c|}{$\begin{array}{l}\text { Transformation of the cohort-sequential design into the accelerated longitudinal design } \\
\text { Full span of ages covered and wave of assessment for each cohort }\end{array}$} \\
\hline & 1 & 2 & 3 & 4 & 5 & 6 & 7 & 8 & 9 & 10 & 11 & 12 & 13 & 14 & 15 & 16 \\
\hline Age 1 years & W1 & W2 & W3 & W4 & W5 & W6 & & & & & & & & & & \\
\hline Age 3 years & & & W1 & W2 & W3 & W4 & W5 & W6 & & & & & & & & \\
\hline Age 5 years & & & & & W1 & $\mathrm{W} 2$ & W3 & W4 & W5 & W6 & & & & & & \\
\hline Age 7 years & & & & & & & W1 & W2 & W3 & W4 & W5 & W6 & & & & \\
\hline Age 9 years & & & & & & & & & W1 & $\mathrm{W} 2$ & W3 & W4 & W5 & W6 & & \\
\hline Age 11 years & & & & & & & & & & & W1 & W2 & W3 & W4 & W5 & W6 \\
\hline
\end{tabular}

Note. $\mathrm{W}=$ Wave of assessment. A dummy code to represent each cohort would be included within each pattern to account for potential cohort differences. The missing data that are missing by design are imputed. Adapted from Little (2013). 
Table 2

Example of two items harmonized from 3 different questionnaire versions

\begin{tabular}{|c|c|c|c|}
\hline Questionnaire 1 & Questionnaire 2 & Questionnaire 3 & Harmonized \\
\hline $\begin{array}{l}\text { Last week, approximately } \\
\text { how many hours did you read } \\
\text { with your child? }\end{array}$ & $\begin{array}{l}\text { How many hours do you } \\
\text { spend reading with your } \\
\text { child each week? } \\
0 \text { hours }\end{array}$ & $\begin{array}{l}\text { How many hours a week do } \\
\text { you spend reading with your } \\
\text { child? } \\
0 \text { hours }\end{array}$ & $\begin{array}{l}\text { Weekly reading hours with } \\
\text { child } \\
0 \text { hours }\end{array}$ \\
\hline \multirow[t]{3}{*}{ Open numerical answer } & $\begin{array}{l}1-3 \text { hours } \\
3-5 \text { hours }\end{array}$ & $1-5$ hours & $1-5$ hours \\
\hline & 5-10 hours & 5-10 hours & 5-10 hours \\
\hline & More than 10 hours & More than 10 hours & More than 10 hours \\
\hline $\begin{array}{l}\text { At approximately what } \\
\text { frequency do you physically } \\
\text { punish your child? }\end{array}$ & $\begin{array}{l}\text { How often to you physically } \\
\text { punish your child? }\end{array}$ & $\begin{array}{l}\text { How often do you give a } \\
\text { physical punishment to your } \\
\text { child? }\end{array}$ & $\begin{array}{l}\text { Physical punishment } \\
\text { frequency }\end{array}$ \\
\hline Never & Never & Never & Never \\
\hline Once a month or less & $\begin{array}{l}\text { Less than once a month } \\
\text { Once a month }\end{array}$ & About once a month & Once a month or less \\
\hline A few times a month & A few times a month & $2-3$ times a month & A few times a month \\
\hline Once a week & Once a week & About once a week & Once a week \\
\hline A few times a week & Several times a week & $\begin{array}{l}2-3 \text { times a week } \\
3-6 \text { times a week }\end{array}$ & A few times a week \\
\hline $\begin{array}{l}\text { Once or twice a day } \\
\text { Several times a day }\end{array}$ & Every day & Every day & Every day \\
\hline
\end{tabular}

